\title{
The Quality Assurance of High-Quality Innovation Professional Postgraduate for Optimizing Incentive System
}

\author{
Ge YANG $^{1}$ and Yong-ping YANG $^{1}$ \\ ${ }^{1}$ Beijing Normal University (Zhuhai Campus), Institute of Information Technology, \\ Zhuhai, China, 519087
}

Keywords: Internal and external quality assurance system, Incentive system, Incentive Model.

\begin{abstract}
In this paper the concept of motivation and incentive system, and the management science theories related incentives were proposed. The internal and external quality assurance models and incentive system model implementation were analyzed. Finally, some specific applications of this model were discussed under the guidance of the three motivation theories.
\end{abstract}

\section{Introduction}

The professional graduate quality problem has been in doubt. Through open duration and education system to foreign postgraduate, summed up the foreign postgraduate education quality guarantee main characteristics is carried out through the external quality assurance, including various forms of assessment, certification and enterprise cooperation, joint training and so on. The different countries are not the same. The main difference lies in the appraisal department, evaluation agency, evaluation implementation process, evaluation standard and form.

From the process of higher education development, the research on the quality of the external guarantee institutions of the graduate education has included the government, social and academic organizations, enterprises, institutions, and so on. Internally, refers to the training unit itself. With this internal and external quality assurance system, and the help of the relevant incentive theory of management, you can provide guidance for the follow-up of the incentive system to establish incentive model.

\section{The Incentive System for the Professional Postgraduate}

\section{(1)Demand hierarchy theory}

American social psychologist Abraham Maslow in his foundation book motivation and personality, people's demand level is divided into five levels and their relationship is compared to the pyramid. From the bottom to the top of the tower, the five levels of demand are: physiological needs, safety needs, social needs, esteem needs and selfactualization needs.

According to Maslow's view, the human need is arranged in a certain order. Maslow's theory clearly divided human needs, for the complexity of human, although there are limitations but also finally is basically explains the relationship of human motivation and demand. It has certain guiding significance for the establishment of the incentive system of the innovative professional postgraduate [1]. Xu Jinsheng translation theory of Maslow's hierarchy of needs that Maslow sees the importance of cognitive and aesthetic need, but he did not explicitly to subsumed under the hierarchy, that they are not like the fifth as, has obvious advantages property in the hierarchy [2]. 


\section{(2)Expectation theory}

American psychologist Victor vroom from the consideration of the behavior of the individual, that the degree of a person to complete the objectives and expected to bring their own value, and can achieve the possibility to target the desired product, determines the goal brings to the individual incentive [3], incentive force, It is determined by the following formula (1):

$\mathrm{M}=\mathrm{V} \times \mathrm{E}$.

Among them, $\mathrm{M}$ represents the Motivation, $\mathrm{V}$ represents the Value, $\mathrm{E}$ represents the Expectance, is a probability value. By the formula, we can improve the $\mathrm{V}$ and $\mathrm{E}$ value, only when the two values are relatively high. It is possible to fully stimulate people's action. In the same way, we can learn to use the $\mathrm{V}$ value and $\mathrm{E}$ value of the incentive system to improve the training quality of students. The so-called 'incentive' is to stimulate people's motivation, make people have an inherent power, to the desired development goals, a mental activity process. At present, Chinese incentive system is still not perfect, to improve the quality of postgraduate training, it is necessary to optimize incentives [4].

(3)Reinforcement theory

American psychologist Skinner is pay close attention to the relationship between behavior and results. He believes that people usually take some action on the environment behavior to achieve a certain purpose. If the situation on his behavior produced favorable information feedback, then he will repeat to take the action; on the contrary, if the adverse response, this behavior will gradually reduce or even disappear. According to Skinner, the concept of "positive reinforcement" and "negative reinforcement" is put forward, and the organization can modify the behavior of individual by controlling the result of different behaviors.

Combined with management motivation theory and professional graduate training in the process of actual, some scholars earlier is in how to make the process of motivation effect, different degree, different angles in-depth thinking. Scholar Shan Wen ye use theory of hierarchy of needs, to study the students need to have high and low level, diversity and changeability of the characteristics are discussed, with an emphasis on graduate incentive mechanism to consider the demand for high-level "multiplier effect" [5]. Zhang Guoli take the case analysis of the way, for the university scientific research team's incentive problem, put forward the incentive model is divided into two aspects of internal and external incentive [6].

\section{The Characteristics of Incentive System of University Postgraduate in China}

Through the observation, summary and analysis of the relevant scholars in China, we have found that the existing incentive system in China has the following characteristics:

Through establishing an incentive mechanism, form a excited, self and mutual excitation unified pattern, instead of in the past, "Lai" "by", one-way walk, graduate Education Management "one Yuan" incentive situation[7]. Chinese university postgraduate education directly or indirectly involved in postgraduate training personnel working process including: students, school educators, cultivation management staff of the unit, the government education department related personnel, enterprise personnel and concerned about postgraduate training of the community.

Whole course is referring to the incentive system of the professional postgraduate training, in various aspects of the work. The beginning of the operation of the system of 
professional postgraduate is the beginning of the study. Subsequently, in the initial stage of culture, culture medium, and the latter is concomitant all the time.

Comprehensiveness, some domestic scholars believe that the comprehensive incentive is the postgraduate training, unit comprehensive supporting use the positive incentives and negative incentives to stimulate the postgraduate[8]. From the incentive effect of classification can be divided into positive incentives and negative incentives; from incentive form of classification can be divided into material incentives and spiritual incentives; from the incentive effectiveness classification can be divided into short-term incentives and long-term incentives.

\section{Incentive Mode}

According to the description of the front, after years of development, different regions of the developed countries, all according to the actual situation of their own countries, summed up a professional study of quality guarantee system.

In the incentive model, it should be divided into the external system and the internal system to discuss the incentive of the object. In the internal system, the objects involved are students, school departments, scientific research teams and mentors. The external system involved government departments, business units, social organization and family friends of the postgraduate.

Thus, the integrated external system and the internal system of each object, a total of more than 21 pair impact of the relationship. Derivative of institutions, organizations, the platform has occurred between the internal system and external system. For example: state and internal training unit of the joint laboratory, corporate research base, based on online teaching resources sharing MOOC (massive open online course) platform, enterprise and University United Graduate School, and so on. These derivatives become the internal system and the external system of collaborative training, information feedback to achieve complementary advantages of the bridge.

Finally, the two major systems are the same as the training process of the professional postgraduate. Therefore, this model is composed of various object relations and process object, and M.O.P (Module of Object and Process) model.

\section{The Concrete Application of the Incentive Model}

\section{A.M.O.P Model in the Theory of Demand hierarchy}

According to Maslow's point of view, in five human needs, physiological needs and security requirements are divided for lower needs, and social needs, respect needs and self actualization needs are divided for high needs. Obviously lower meet the demand is temporary, it is for the transition to senior needs and services; and to meet the high demand is endless, and the satisfactory level is difficult to meet people's expectations.

Internal system of students, for example, some of them from the poor economic situation is not very good family, first came to the university students enrolled in professional research, the cost of living is undoubtedly a problem can not be avoided. Although actually this kind of postgraduate due to poor birth, and with stronger enterprising spirit and a sense of crisis than other students, but if long-term living trapped, is bound to affect their professional research process more or less.

Therefore, to meet the needs of the low level of the object in the model, it is the basis of the M.O.P model. But the only focus on meeting the needs of the low level of the object, it will produce some potential problems. To meet the material needs of survival, 
on the one hand, can't produce a lasting and effective incentive effect for the objects. On the other hand, it does not accord with the actual situation of some colleges and universities in underdeveloped areas.

Step back, even if these regions can gain lasting stability of external system of material assistance, go down for a long time is also bound to every object, lost crisis consciousness and enterprising spirit and become lust for smooth in the internal system, not innovation. Therefore, the need to meet the low level basis needs should be more to stimulate them in the pursuit of higher levels as the goal. For example, the needs of career planning, research in the field of professional and senior members of the exchange advice needs can get more extensive scientific breakthrough platform needs, master professional society of comprehensive quality of demand and so on.

Through the analysis of the psychological characteristics of the postgraduate, the characteristics of the population in China are characterized by diversity, variability and reality. All in all, according to the philosophy, need to grasp the main contradiction of the current incentive object, to meet their most urgent need for the first. For example, some students at the beginning of school, eager to settling down, then solve their basic necessities of life is first and foremost; until after the material basis is stabilize, they eager to understand this new environment, into the new environment, to make friends, have their own circle, obtains the sense of belonging sense, a sense of security; academic things progress to a certain degree, due to the research of gradually into the right track and eager to find in their field of study, can be further exchange of learning platform, hope to get the teacher's guidance, team help and so on. To the late, near the graduation thesis and work on the agenda, at this time and in particular they need to guide from parties.

Through the analysis, we can know that the demand of emergency is not fixed, but has the flexibility and the change. So if the material and safety need to be set for the current most urgent need for self-realization, scientific research work achievement is the need for a long time. The model should pay attention to timely distinguish other individuals, to give incentives for timely to meet the psychological needs of students under which, at the same time be focused to take into account the long-term nature of the demand.

\section{B.M.O.P Model under the Expectation Theory}

(1)The effect of internal training and scientific research

According to prior to the introduction of Victor vroom's expectancy theory and formula, a person on the target value (potency) estimates that the larger the estimated likelihood of achievement of objectives (desired) increases, then the greater the power of their excitation. To generate incentives effect among the various objects, M.O.P model must increase the potency and expected value as the motivation object to the various factors in the process of training, but also two values to improve the incentive effect on the object. For the teacher, to do the work is at the beginning of the entrance on the early to students introduced the direction of the professional research trend at home and abroad, research progress and market demand description, let the students know the direction of their own choice; at the same time, the training may be arranged to process such as domestic and foreign joint training of high school, research and communication, and also to allow students to clearly, let the students can independent judgment. Internal research team members help each other, collaborate on research work can also improve students' individual potency and expectations.

(2)The influence of industry university research base on the cultivation of talents 
Chinese colleges and universities with combination integration strategy has become a trend, psychological graduate populations of the foregoing, the majority of graduate group psychology has matured and reality. So it is necessary to improve the enthusiasm of the students in the course of the study, and it is necessary to introduce the enterprises in the external system. This has the following benefits: companies can provide resources for the relatively more abundant practice platform. At the same time, colleges and universities can also provide scientific research and technology development for the enterprise unit of Sony in. Base of industry, University and research collaborative culture, enterprise has experienced technical development staff and school teacher consisting of more than group instructors, and ultimately realize the complementary advantages of resources of schools and businesses. Students in university culture are introduced in the procedure of enterprise participation and have confidence to the direction of my research. In the training base in further training, their ability of scientific research practice, broaden their vision. The result is that under the influence of high efficiency and high expectations, the results of the M.O.P model are obviously improved.

(3)Assessment of the internal system of institutions

Learn from the America's mature developed external evaluation mechanism, assessment agencies will undoubtedly have a positive assessment of the M.O.P model will have a certain impact on the parties. In the United States, the external quality assessment committee often not regularly to the internal culture quality assessment, used to formulate prior good, recognized standards of various colleges and universities education quality ranking, ranking results through the news media to inform the public. According to the expectation theory, the evaluation of the institution has changed the value of the external system of the M.O.P model to the expectations of the internal system. The government and enterprises can see the evaluation institution of different colleges and universities in the training of graduate students from the objective evaluation. One of the functions of the school is social services including using the talents of high quality output to meet the needs of country and society. The government can use administrative means in Colleges and universities and the enterprise can use financial, human and material resources and so on supporting construction of colleges and universities.

\section{C.M.O.P Model of Reinforcement Theory}

In view of the model involves the cultivation process constitutes a multi object relation and a variety of factors, and inside and outside the system of arbitrary objects have may become the object of incentive, the relationship between each other is interdependence and mutual influence, fair, just and reasonable rewards will have a positive impact on training effect. According to reinforcement theory, through the object of positive reinforcement, will promote the toward the organization expected goals continue to work hard, and negative reinforcement can make the stimulated object awareness organizations don't want what kind of behavior, thus reminding and try to avoid developing in this direction.

In the case of students at the center of the internal system, for example, the source of the student's reward can be any other object in the model. This award includes material rewards and spiritual rewards. Material reward more refers to the scholarship, financial incentives. Grant is usually the government, school departments, business units, etc. These have a certain economic capacity of the organization. Fund awards should be based on the performance of different students and different, there should be a certain 
degree of division. The average reward is not an incentive. Because the object will have different psychological feedback in the comparison, so as to produce the power to make it better. Spiritual reward is to the students in the process of scientific research in the outstanding performance, in a timely and effective for the students, at the same time in the study of the emotional life of the low period of emotional care.

\section{Conclusions}

In this paper, we discusses the domestic and foreign training mechanism, the quality, and the quality assurance system of domestic and foreign students, introducing the basic theory of incentive system and the feature of postgraduate incentive system in China, according to the establishment of the inside and outside of the system model, and the theory of incentive, with the help of the inside and outside the system's basic structure, Established Chinese professional research and corresponding students inside and outside the system and training process is composed of incentive model, and discuss some applications of the incentive mode, which under the guidance of the incentive theory, for our graduate professional training work with a humble.

\section{Acknowledgements}

This research was financially supported by Guangdong Provincial special funds Project for Discipline Construction (No.2013WYXM0122); Guangdong Provincial College Innovation and Entrepreneurship Project (201413177035, 201513177028); The Special Development Funds Project for Strategic Emerging Industry of Shenzhen(No. JCYJ20120614144655154); Twelfth Five-Year Plan (2015-2016 Projects) for philosophy and Social Sciences of Zhuhai (2015YB016)

\section{References}

[1] Dong Ke. Introduction to human resource management [M]. Renmin University of China press, 2012:54-56.

[2] [US] Abraham Maslow with, Xu Jinsheng ect. Motivation and personality (Third Edition) [M]. Beijing: China Renmin University Press, 2007(In Chinese).

[3] Zhou Sanduo. Management [M].Higher education press, 2012:252-253.

[4] Yan Ying. Analysis of the incentive mechanism of postgraduate[J]. education and career, 2013 (3): 31

[5] Ye Shanwen. The research on the incentive mechanism of the graduate students based on the theory of hierarchy of needs [N]. Journal of Ningbo University, 2007-8 (4).

[6] Zhang Guoli. The research team in the university research team[D]. Wuhan: Huazhong University of Science and Technology, 2007:1(In Chinese).

[7] Liu Dongmei, Yuan Xiaojie. Construction of a demand oriented graduate education incentive mechanism[J]. Science and technology market, 2008, (1): 65-66.

[8] Liu Xinfang. Study on the incentive mechanism in the cultivation of postgraduate [D]. Guangxi: Guangxi Normal University, 2014:12(In Chinese) 